Article

\title{
Scenario Analysis on the Generation of End-of-Life Hybrid Vehicle in Developing Countries-Focusing on the Exported Secondhand Hybrid Vehicle from Japan to Mongolia
}

\author{
Shuoyao Wang *, Jeongsoo Yu $\mathbb{D}$ and Kazuaki Okubo \\ Graduate School of International Cultural Studies, Tohoku University, Sendai 9808576, Japan; \\ jeongsoo.yu.d7@tohoku.ac.jp (J.Y.); kazuaki.okubo.d5@tohoku.ac.jp (K.O.) \\ * Correspondence: wang.shuoyao.q7@dc.tohoku.ac.jp; Tel.: +81-80-5842-6688
}

Received: 16 September 2019; Accepted: 15 October 2019; Published: 15 October 2019

check for updates

\begin{abstract}
In recent years, Next-Generation Vehicles, especially Hybrid Vehicles (HV) are increasing rapidly in advanced countries. In fact, not only advanced countries but also some developing countries also own a large quantity of HV by importing secondhand HV from advanced countries. For instance, Mongolia is importing a huge amount of secondhand HV from Japan every year. On the other hand, there will be a huge amount of waste HV in Mongolia that needs to be recycled properly soon, and yet, this problem has been neglected and the number of waste HVs in Mongolia is still unknown. The purpose of this research is to propose a method to predict the End-of-Life HV number in Mongolia. This research finds that the Japanese vehicle deregistration rate can represent vehicles' durability and can be used to estimate End-of-Life HV number in Mongolia. The result shows that there will be a huge amount of End-of-Life HV as well as Nickel-Metal Hydride (NiMH) batteries generated in Mongolia from now on, even more than in Japan, which is the largest HV market. It is urgent for the Mongolian government to build a proper End-of-Life HV recycling system now, and international cooperation on resource circulation is also expected.
\end{abstract}

Keywords: scenario analysis; End-of-Life hybrid vehicle; developing country; secondhand vehicle exportation; Japan; Mongolia; nickel metal hydride battery; deregistration rate

\section{Introduction}

In recent years, along with motorization around the world, the increasing emission of $\mathrm{CO}_{2}$ became a problem, in fact, nearly $25 \%$ of the $\mathrm{CO}_{2}$ emission is from the transport sector [1,2]. Moreover, since the vehicle stock number around the world will be even larger in the future, the massive consumption of fossil oil will also be a new issue [2,3]. Therefore, to solve such problems, many advanced countries, such as the U.S.A, European countries and Japan, started to develop Next-Generation Vehicles, which will reduce $\mathrm{CO}_{2}$ emission during the running process, and consume less gasoline at the same time [3,4]. Although there are many kinds of Next-Generation Vehicle, the most well-sold one is the Hybrid Vehicle (HV). Among all the advanced countries, Japan is the largest HV market and occupied about $66 \%$ of global HV sales in 2017 [5,6]. However, besides advanced countries, there are also some developing countries trying to develop Next-Generation Vehicles to solve severe air pollution problems from the transportation sector. The most typical case is Mongolia. However, since Mongolia does not own their own automobile manufacture business, they are importing a large quantity of secondhand HVs from Japan to improve their air quality. In fact, from 2017 to 2018, among all the exported secondhand HVs from Japan, 23\% to 24\% was exported to Mongolia, this proportion could be even larger in 2019 [7]. 
On the other hand, these secondhand HVs are of low quality generally, and so, there will be a huge amount of $\mathrm{HV}$ in Mongolia waiting to be recycled properly in the future, otherwise, a huge amount of resources will be wasted completely [8]. Moreover, not only the End-of-Life HVs but also the waste NiMH batteries need to be collected, reused and recycled efficiently; if not, there could be severe resource waste or even environmental pollution problems [9-12]. However, the number of End-of-Life HVs and NiMH in Mongolia has not been grasped yet, and so it is hard to install a proper and efficient End-of-Life Hybrid Vehicle recycling system.

In response to this background, this research aims at proposing a method to estimate End-of-Life $\mathrm{HV}$ as well as NiMH number in Mongolia. The result shows that there will be numerous End-of-Life $\mathrm{HVs}$ and NiMH batteries needing to be recycled in the future, a proper recycling system and cooperation between developing countries and advanced countries is expected.

\section{Materials and Methods}

\subsection{Hypothesis on the Operable Method to Estimate End-of-Life HV Number in Mongolia}

Normally, End-of-Life Vehicle (ELV) number can be estimated by Weibull distribution [13-15]; in fact, Yano et al. (2016) have estimated the End-of-Life HV disposal rate in Japan using Weibull distribution already [14]. However, to estimate the ELV number using Weibull distribution, detailed information such as the number of HV stock and registration number in Mongolia every year have to be grasped to calculate HVs' remaining rate in Mongolia first. However, such data is quite hard to access.

Therefore, it is hard to estimate End-of-Life HV number using ordinary methods. On the other hand, since most secondhand HV in Mongolia were imported from Japan, the method to estimate End-of-Life vehicle number in Japan can be referenced.

According to the Automobile Inspection \& Registration Information Association (Japan), the average age of End-of-Life Vehicle in Japan is 13 years [16]. This is because Japan has a mandatory vehicle maintenance program, passenger vehicle owners are asked to check their vehicles at authorized stores. The first time for the vehicles' maintenance is in the third year after the vehicles' first registration and will be every two years after that. The vehicle maintenance program is quite expensive and became a reason why vehicle owners disposed of their vehicles [17]. Moreover, from 2014, the Japanese government started to levy more tax on vehicles older than 13 years [18]. It is now clear that the disposal time of ELV in Japan shares a connection with the duration of the vehicle maintenance program and tax regulation (Figure 1), and consequently, most vehicles in Japan will be disposed in the 13th year of usage [19].

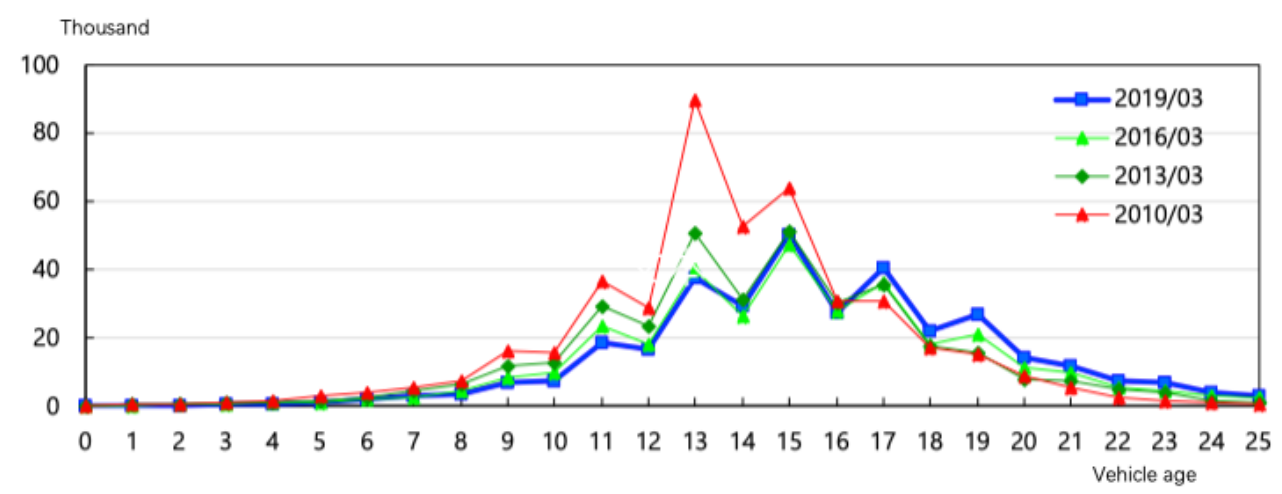

Figure 1. Age of recycled End-of-Life vehicle in Japan. Source: Japan Automobile Recycling Promotion Center (JARC) [19]. Note: Figure 1 is made by Japan Automobile Recycling Promotion Center originally.

However, even so, there will also be around $40 \%$ of vehicles being left after the 13th year since their first registration (Figure 2) [20], and it is fair to say that these vehicle owners are disposing their car due to the degradation of vehicle performance instead of due to economic factors. That is to say, if there 
were no such expensive and mandatory vehicle maintenance program, vehicles manufactured in Japan can be used for about 30 years. And so, the actual vehicle deregistration rate can also representative Japanese vehicles' mechanical durability.

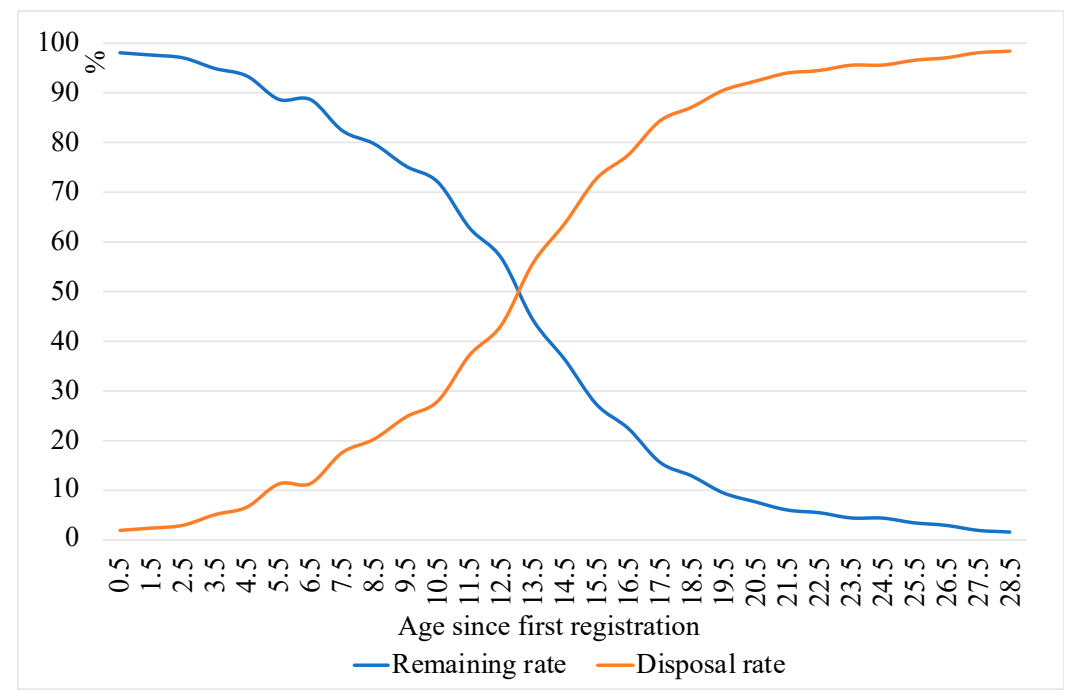

Figure 2. Deregistration rate of vehicle in Japan. Source: Figure made by the author based on Automobile Inspection \& Registration Information Association's data [20].

On the other hand, as mentioned before, Figure 2 shows vehicles' deregistration rate, and deregistered vehicles can be divided into 3 kinds of vehicles: ELV; secondhand vehicle on the domestic market; and exported secondhand vehicles [21]. However, it is believed that the vehicle maintenance industry in Mongolia is in arrears, and once a high-tech HV has broken, it is hard for technicians in Mongolia to fix the vehicle. Also, this research assumes that secondhand HVs exported to Mongolia are hard to export to another country again. In other words, the vehicle deregistration rate in Japan can be representative of the Mongolian vehicle disposal rate.

Therefore, in this research, we assume that the disposal of secondhand HV exported to Mongolia should follow the distribution in Figure 3.

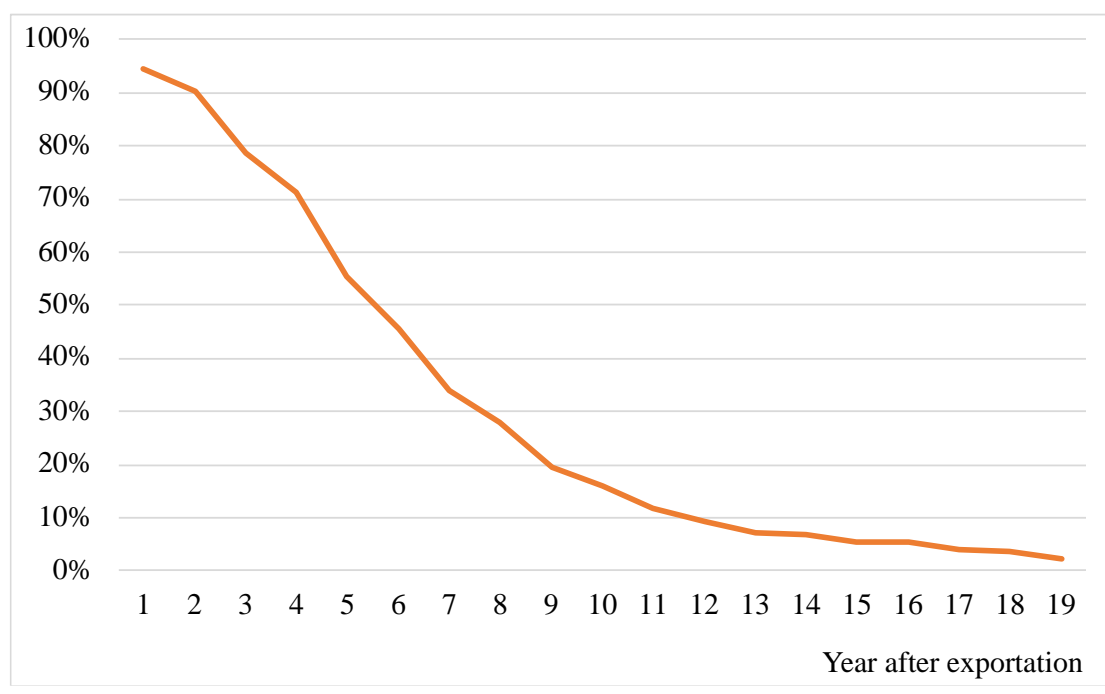

Figure 3. The remaining rate of secondhand hybrid vehicles (HVs) exported to Mongolia. Source: Figure made by the author based on Automobile Inspection \& Registration Information Association's data [20]. 
And so, in the observation year, the number of End-of-Life HVs manufactured in a specific year $(\mathrm{Y})$ is calculated by Equation (1):

$$
Y=R_{x-1} \times E_{x}-R_{x} \times E_{x}
$$

where $R_{x}$ stands for the remaining rate of vehicles which has been used for $x$ years, and $E_{x}$ stands for the number of exported secondhand $\mathrm{HV}$, which has been used for $x$ years. The next step is to investigate the age of exported secondhand HV to Mongolia to decide where the calculation should start.

\subsection{Method to Presume Exported HVs' Age}

Although there are a few documents showing the age of secondhand HVs exported to Mongolia, it is widely believed that these secondhand HVs can be quite old and can have been used for over 15 years already [10]. On the other hand, generally, the price of a secondhand vehicle can reflect how long the vehicle has been used (Figure 4) [22]. Therefore, this research will use the average price of exported HV from Japan to Mongolia to estimate their age. The Japan Custom started to record the average price of exported HV, it shows that from 2017 to July 2019, the average price of secondhand HV exported from Japan to Mongolia stables around 370 to 390 thousand Japanese yen (Figure 5) [7]. This means that most of these exported vehicles have been used for about 9-10 years (Figure 4). In this research, we assume that the secondhand Vehicle exported to Mongolia has been used for over 10 years, this is also the time when most of the Japanese vehicle owners started to discard their vehicles (Figure 1). Moreover, we will further perform a scenario analysis on the exported $\mathrm{HVs}^{\prime}$ age. In the scenario analysis section, we assume the age of exported HV from Japan is 15 years. The next step is to estimate the annual secondhand HV exportation number from Japan to Mongolia.

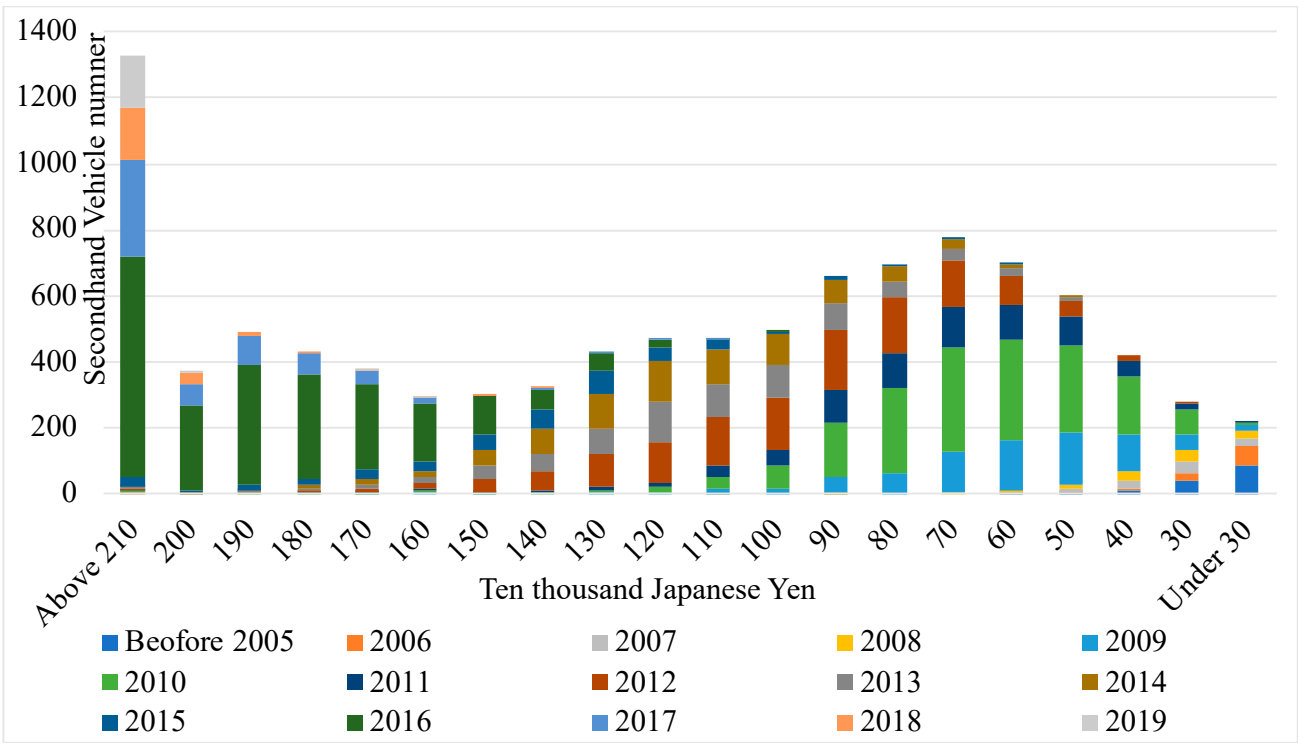

Figure 4. Price of secondhand HV (Prius) of each age in Japan. Source: Figure made by the author based on Carsensor's data [22]. 


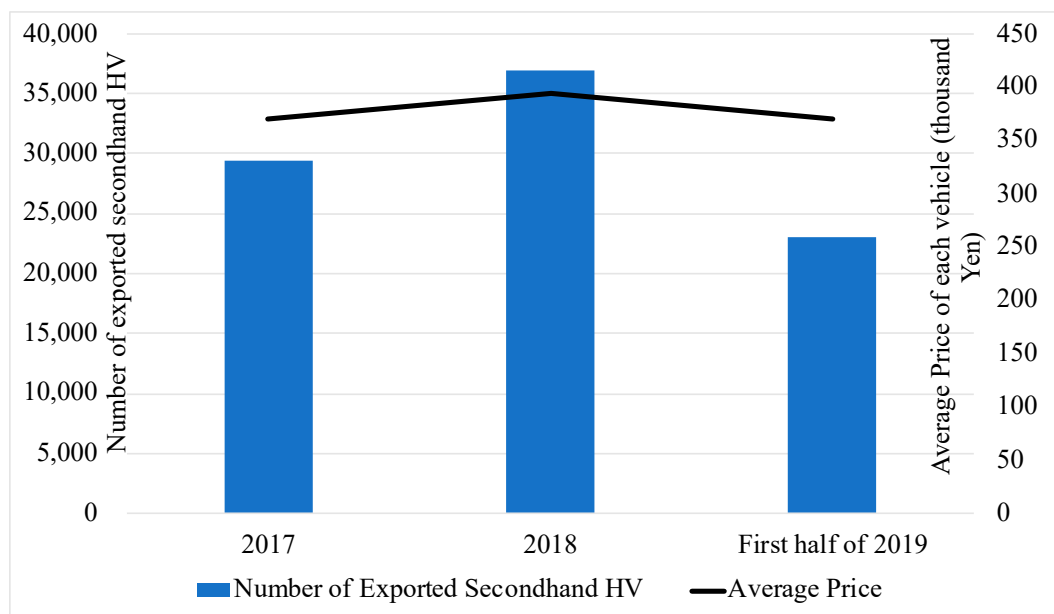

Figure 5. The average price of exported secondhand HV to Mongolia. Source: Figure made by the author based on the data from Trade Statistic of Japan [7].

\subsection{Method to Estimate the Number of Secondhand HV Exported from Japan to Mongolia}

Secondhand HV importation number in Mongolia from 2007-2014 was referenced from Nippon Steel [23]. Although this data is the secondhand HV trading data between Mongolia and the world, during that period, most secondhand HVs were generated by Japan. Also, geographically, Japan is closer to Mongolia than other countries. Therefore, these data are treated as the secondhand HV trading data between Japan and Mongolia only.

Secondhand HV exportation data from Japan to Mongolia between 2017 and 2018 were referenced from the document published by Trade Statistics of Japan [7]. Also, since the HV exportation data in 2015 and 2016, and the data related to future secondhand HV exportation from Japan to Mongolia is lacking (from 2019 to 2030), it will be forecasted using the Approximate curve; the same method has been used in the previous study as well [15]. The actual number and estimation number of secondhand HV exported from Japan to Mongolia is shown in Figure 6. According to the assumption, secondhand HV exportation from Japan to Mongolia will reach 140,000 in 2030.

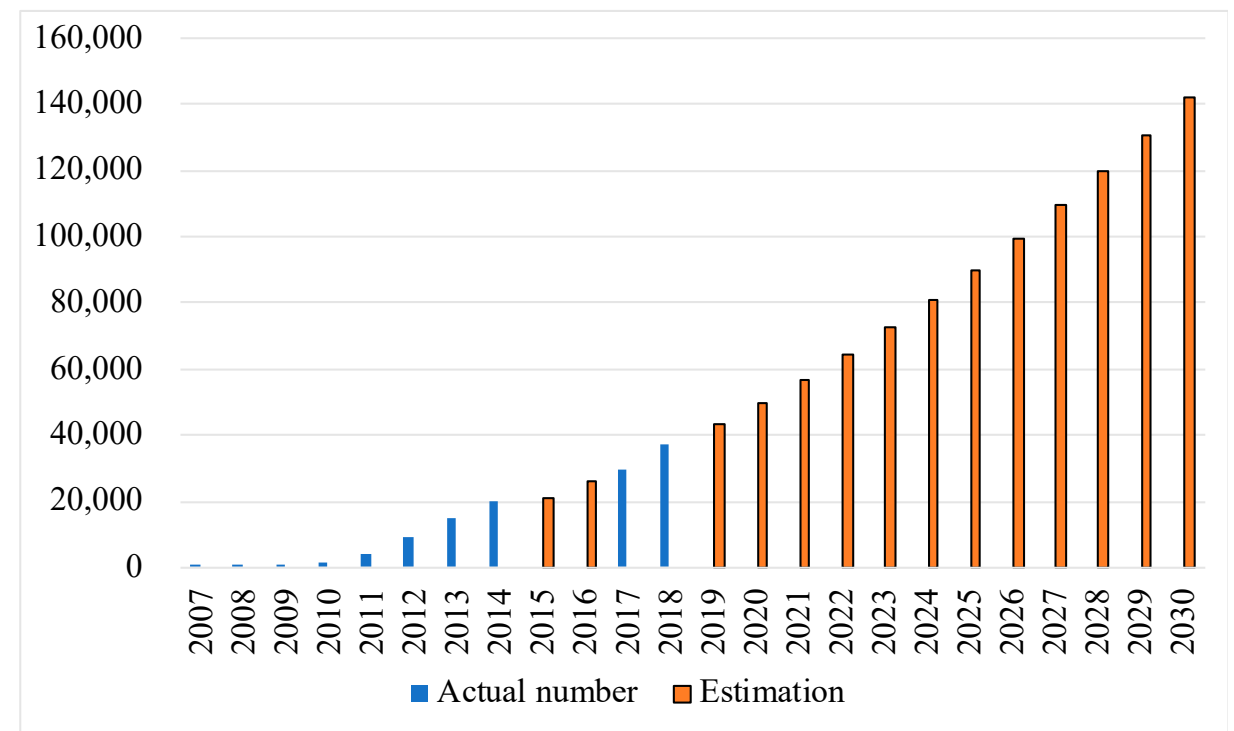

Figure 6. Actual number and estimation of secondhand HV exportation from Japan to Mongolia. Source: Figure made by the author based on the data from Nippon Steel and Trade Statistic of Japan [7,23]. Note: $\mathrm{R} 2$ of the approximate curve is 0.9807. 


\subsection{Waste NiMH Generation in Mongolia}

Although the HV made in Japan can be used for 30 years, the NiMH used in HV cannot be used for such a long time and will have to be replaced during the usage process. The serviceable year of NiMH battery is estimated to be around 15 to 20 years [10,24]. And after that, the NiMH battery will be replaced. Since the brand-new and authorized battery is rather expensive and so unaffordable for Mongolian people, the HV owners in Mongolia may use a remanufactured NiMH battery. The serviceable age of the remanufactured NiMH battery is considered to be around 5 years for the maximum situation [25].

\subsection{Method to Estimate Environmental Effect of Reusing NiMH Battery in Mongolia}

Currently, Mongolia has no advanced vehicle recycling technology to recycle NiMH batteries [10] so all the End-of-Life NiMH batteries are being landfilled directly and will cause severe problems. However, if part of these waste NiMH batteries can be reused, the amount of waste NiMH battery will be largely reduced [12]. In this research, we focus on the waste reduction effect to analyze the environmental effect of reusing NiMH batteries in Mongolia. According to the data published by previous studies [26], as well as our field survey on NiMH battery remanufacturer in Japan in 2017, the weight of the latest NiMH battery in an $\mathrm{HV}$ is around $40 \mathrm{~kg}$. And so, the environmental effect (tons) of reusing NiMH battery in Mongolia (W) is calculated as Equation (2):

$$
\mathrm{W}=(\mathrm{N}-\mathrm{Nr}) \times 40 / 1000
$$

where $\mathrm{N}$ demonstrates the number of waste $\mathrm{NiMH}$ batteries without reuse, $\mathrm{Nr}$ stands for the number of waste NiMH batteries with reuse, and 40/1000 will transfer the result from $\mathrm{kg}$ to tons.

\section{Results}

As the result shows, in 2020, there will be around 21,000 End-of-Life HVs in Mongolia, and this number will expand to around 86,000 in 2030 (Figure 7).

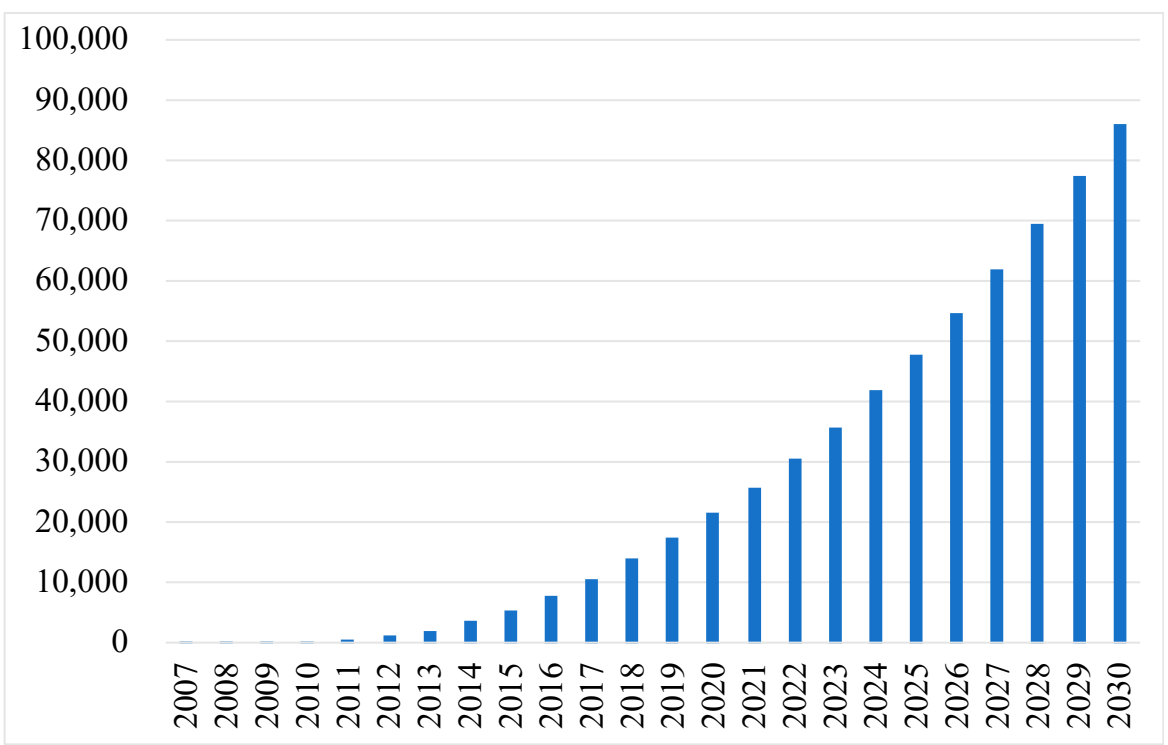

Figure 7. Estimated End-of-Life HV in Mongolia. Source: Figure made by the author based on the information from Automobile Inspection \& Registration Information Association; Nippon Steel and Trade Statistic of Japan $[7,20,23]$. 
On the other hand, the number of waste NiMH batteries can be largely affected by their lifespan. When the lifespan of the original NiMH in an HV is 20 years, the number of End-of-Life NiMH is only 2000 in 2020 and will expand to about 71,000 in 2030. In contrast, when the lifespan of the original NiMH is only 15 years, End-of-Life NiMH number will be 20,000 in 2020, almost 10 times larger than the previous scenario. In 2030, the End-of-Life NiMH battery number will increase to 160,000 (Figure 8).

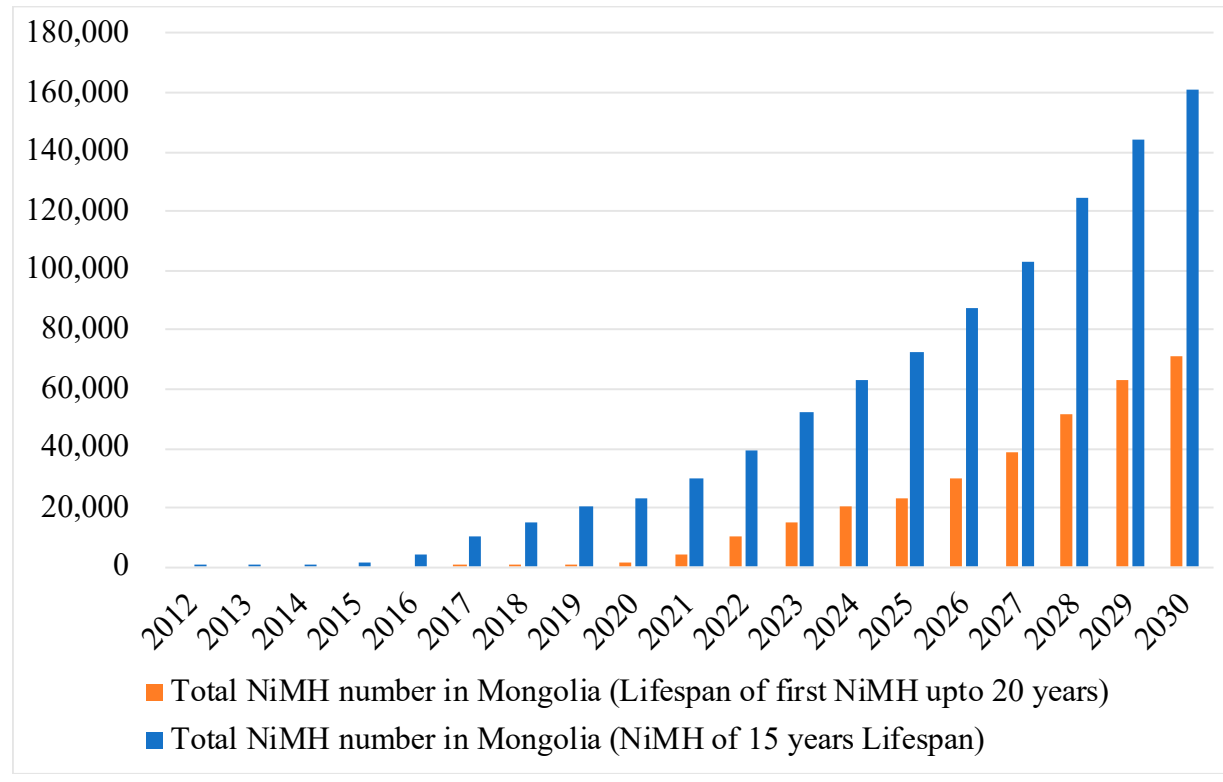

Figure 8. Estimated End-of-Life NiMH battery in Mongolia. Source: Figure made by the author based on the data from previous studies $[10,24,25]$.

\section{Discussion}

\subsection{The Scenario on the Age of Exported Secondhand HV to Mongolia}

As mentioned previously, this section will perform a scenario analysis on the End-of-Life HV number in Mongolia considering that the average age of exported HV is around 15 years instead of 10 years. We investigated secondhand HV exportation number from Japan to Mongolia since 2007. However, the HV was not launched into the market in 1992 (15 years before 2007). Therefore, we assume that the age of exported secondhand HV follows the age shown in Table 1, and the remaining rate for exported HV of each year is shown in Figure 9.

Table 1. Assumption of age for exported HV from Japan to Mongolia.

\begin{tabular}{cc}
\hline Exportation Year & Vehicle Age When Being Exported \\
\hline 2007 & 10 \\
2008 & 11 \\
2009 & 12 \\
2010 & 13 \\
2011 & 14 \\
2012 & 15 \\
$2013-2030$ & 15 \\
\hline
\end{tabular}




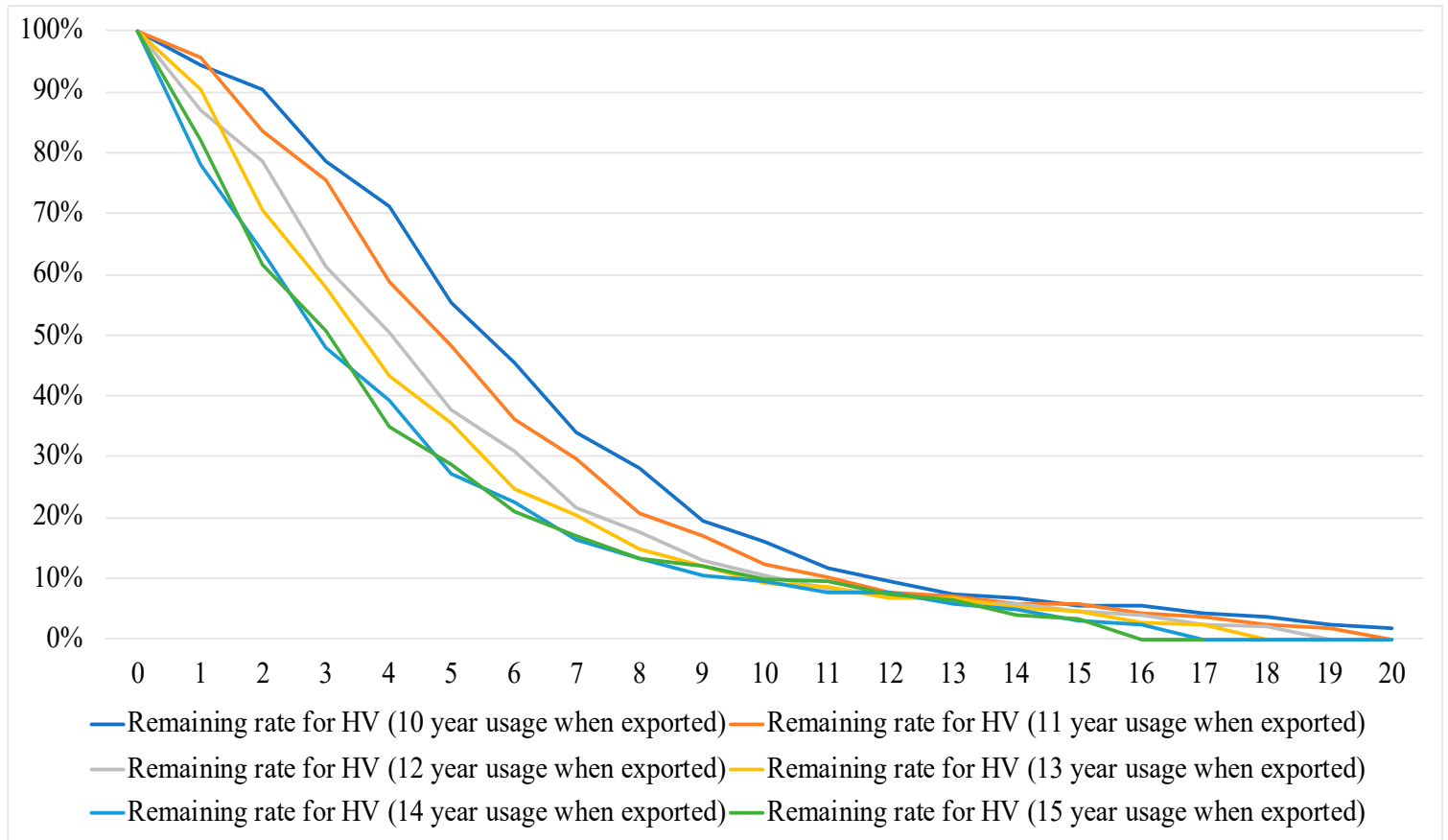

Figure 9. The remaining rate for exported secondhand HV of each year. Source: Figure made by the author based on Automobile Inspection \& Registration Information Association's data [20].

The number of End-of-Life HV in Mongolia for this scenario is shown in Figure 10. It shows that under this scenario, the End-of-Life HV will be around 30,000 in 2020 and will reach nearly 107,000 in 2030 .

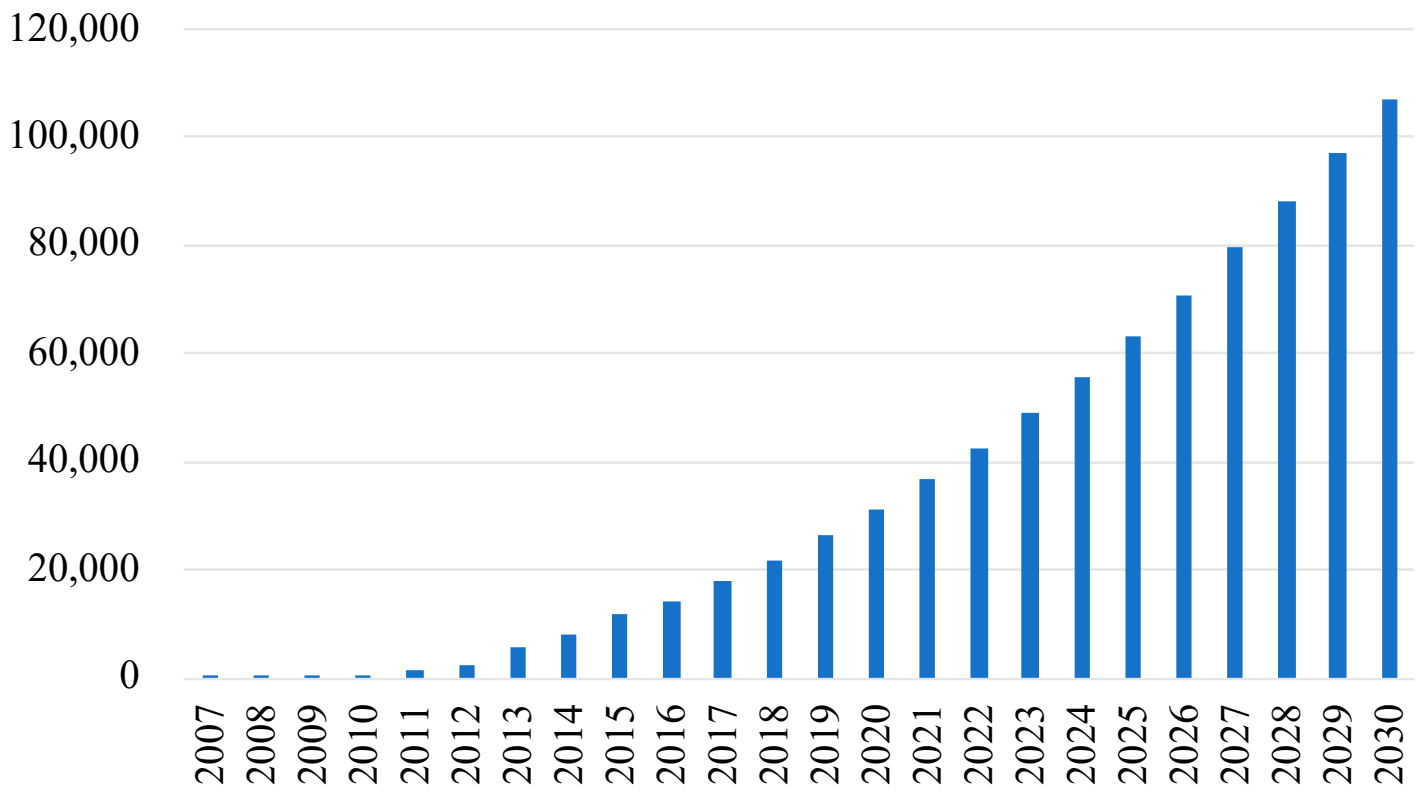

Figure 10. Scenario analysis on the End-of-Life HV number in Mongolia. Source: Figure made by the author based on the hypothesis in 4.1. and data from Automobile Inspection \& Registration Information Association's data [20].

Moreover, according to our interview research on the custom of Japan, secondhand HVs, which are cheaper than 200,000 Japanese yen will not be recorded in the trade statistics. That is to say, secondhand 
HV exported to Mongolia can be larger than the official statistics data and so, the End-of-Life HV in Mongolia should also be larger.

\subsection{The Scenario on the Reuse Rate of Waste NiMH}

It is common that vehicle repair plants pick up usable battery modules from waste NiMH batteries and assemble these modules into a remanufactured NiMH battery. According to our interview research on Japanese NiMH remanufacture operator in 2017, in Japan, about $60 \%$ of modules in the waste $\mathrm{NiMH}$ battery can still be used into a remanufactured NiMH after a strict test. However, the NiMH batteries in Mongolia are older and in a worse situation and may degrade more because of lack of such advanced battery remanufacturing technology. Thereupon, this research assumes that in Mongolia, $40 \%$ to $60 \%$ of NiMH cans still be used in remanufactured $\mathrm{NiMH}$ as a scenario (Figure 11). The result shows the reuse of NiMH module will largely reduce the generation of End-of-Life NiMH in Mongolia to 28,000 units to 43,000 units when the lifespan of the original NiMH was 20 years, or 64,000 units to 96,000 units when the lifespan of the original NiMH was 15 years. Since Mongolia have no End-of-Life NiMH recycling technology, they should promote the reuse of End-of-Life NiMH to delay the generation of waste NiMH.

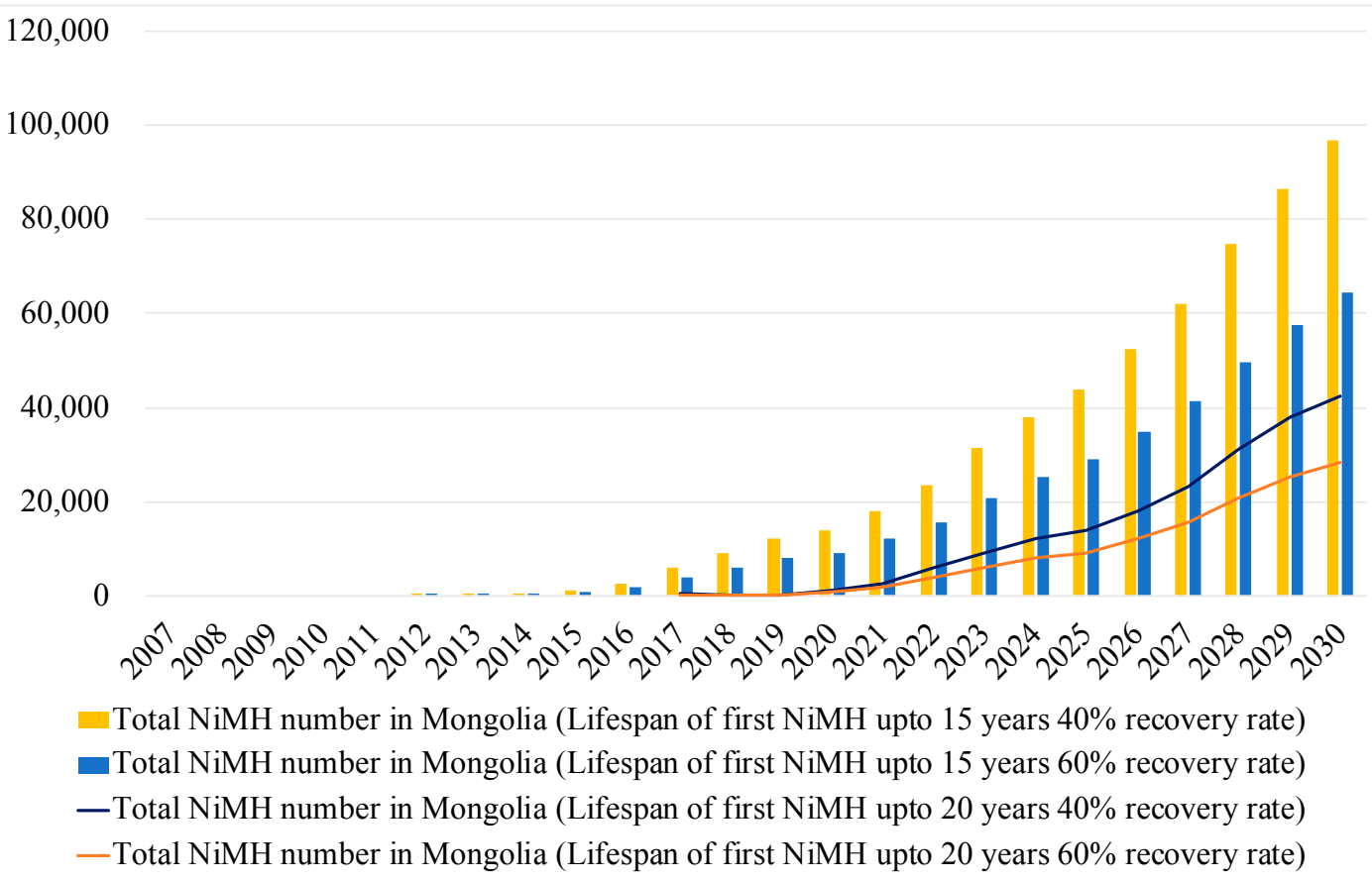

Figure 11. Scenario analysis of waste NiMH number considering reuse rate. Source: Figure made by the author based on Figure 8, and the result on interview research on battery remanufacturer.

\subsection{The environmental Effect from the Reuse of NiMH Battery in Mongolia: Focusing on Waste Reduction Effect}

According to our estimation, by reusing waste NiMH battery, it will reduce 1134 to 1710 tons of solid waste generation in 2030 when the lifespan of the first NiMH was 20 years. Moreover, if the lifespan of the first NiMH battery is only 15 years, the waste reduction effect will be more obvious and will be around 2576 to 3864 tons in 2030 (Figure 12). 


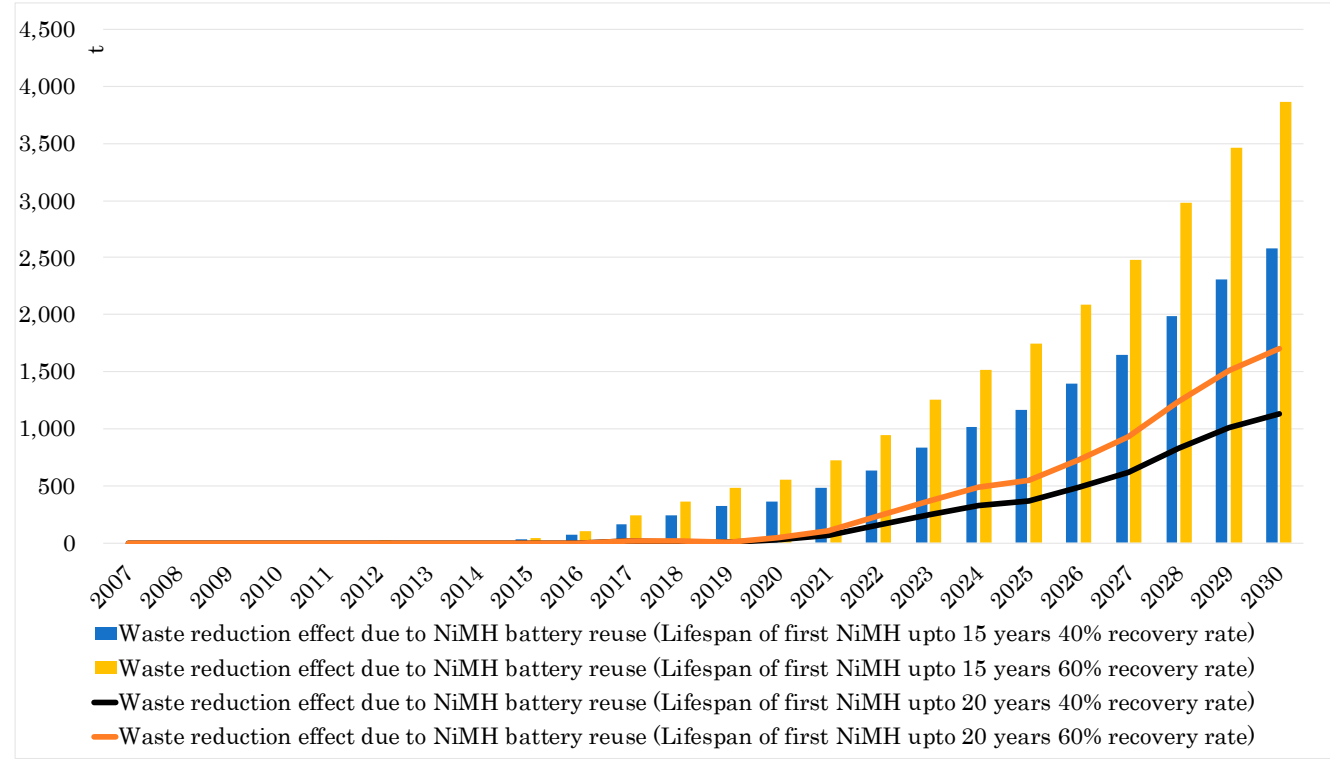

Figure 12. Waste reduction effect due to the reuse of waste NiMH battery. Source: Figure made by the author based on result in Figure 8, Figure 11, and the data provided by previous study [26].

\subsection{Comparison of End-of-Life HV and NiMH Number between Japan and Mongolia}

As mentioned before, Japan is the largest HV market right now, and the Japan government has installed End-of-Life HV and NiMH battery recycling system to recycle resources efficiently. On the other hand, as demonstrated by Japan Automobile Recycling Promotion Center and Japan Automobile Manufacturers Association, the number of End-of-Life HV and NiMH battery recycled in Japan is quite small (Figure 13) [19,27]. Therefore, the End-of-Life HV and NiMH recycling system inside Japan is not running with efficiency as expected, and Japan is losing a huge number of resources due to the exportation of the secondhand vehicle [8]. To recycle more resource from End-of-Life HV and NiMH, Japanese government have to find a way to guarantee the volume of End-of-Life HV and NiMH inside Japan or build an international ELV recycling and resource circulation system with Mongolia.

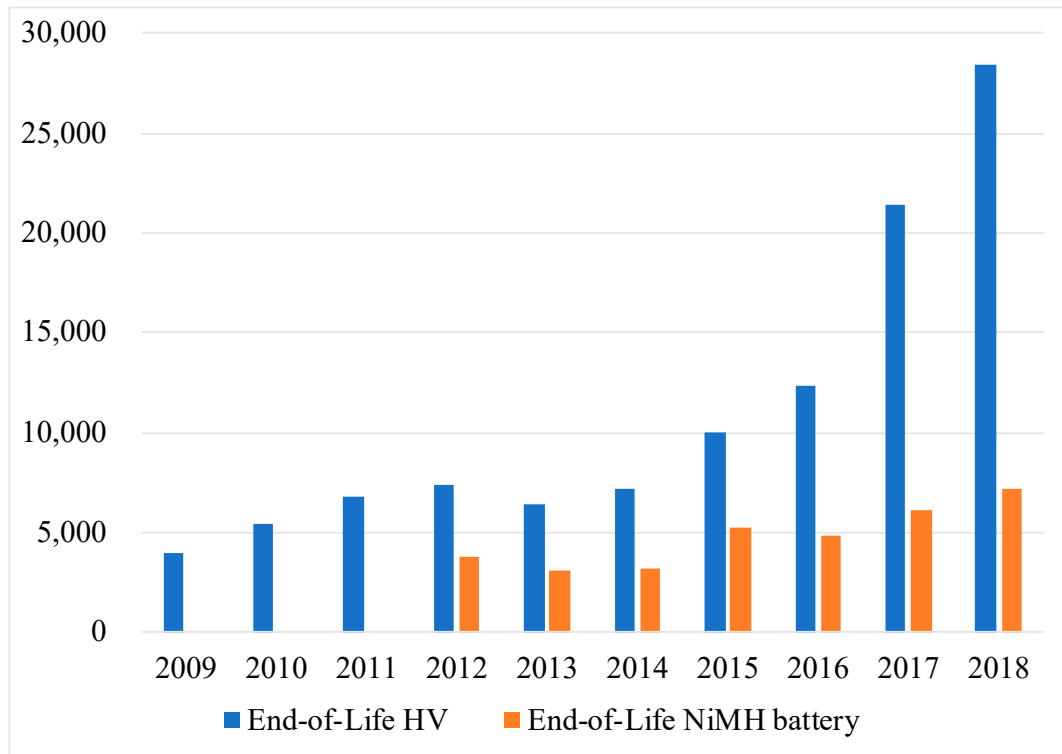

Figure 13. End-of-Life HV and NiMH number in Japan. Source: Figure made by the author based on the data from Japan Automobile Recycling Promotion Center and Japan Automobile Manufacturers Association [19,27]. 


\section{Conclusions}

This research proposed a method to predict the End-of-Life HV and NiMH battery number in Mongolia. The result shows that there will be a huge amount of End-of-Life HV and NiMH battery be disposed in Mongolia. According to our research, the number of End-of-Life HV number in Mongolia should be around 21,000 to 30,000 in 2020 and will expand to 86,000 to 107,000 in 2030. As for the number of waste NiMH batteries, it will be largely affected by the lifespan of the original battery and the reuse ratio. When the lifespan of the original NiMH battery is 20 years, the number of waste NiMH battery can be 2000 in 2020 but will expand to 71,000 in 2030. However, if the lifespan of the original NiMH battery is only 15 years, waste NiMH battery number will increase to 20,000 in 2020, and 160,000 in 2030. The number of waste NiMH batteries will be largely reduced when reuse technology/policy is installed in Mongolia. If the Mongolia government can install waste NiMH battery reuse policy, when the lifespan of the original NiMH battery is 20 years, the number of waste NiMH batteries will be reduced to 28,000 units to 43,000 units in 2030, if the lifespan of the original NiMH battery is only 15 years, with reuse policy, the number of waste NiMH battery in Mongolia will be around 64,000 units to 96,000 in 2030 . Such a policy will reduce 1134 to 1710 (20 years lifespan for original NiMH battery) or 2576 to 3864 (15 years lifespan for original NiMH battery) tons of solid waste for Mongolia.

Also, as for End-of-Life HVs and NiMH batteries, to recycle the resource in these End-of-Life HVs and NiMH batteries properly, the Mongolian government should start to establish their own End-of-Life HV recycling system from now. However, without cooperation with advanced countries, this process may take years, and so, the cooperation between Mongolia with Japan on End-of-Life HV recycling should be put on the agenda as well. On the other hand, the enlargement in HV sales will sure bring increasing demand for certain metal resources. To guarantee these resources, the Japanese government should consider building an international ELV recycling and resource circulation system, which can help Mongolia to recycle and take resources back from these End-of-Life HV and NiMH properly. However, to do so, there should be an analysis on the total environmental and economic effect of such international cooperation (such as Life Cycle Assessment (LCA) and Life Cycle Cost (LCC) analysis) to guarantee the validity, and such analyzation is expected to be performed by future studies.

Author Contributions: Conceptualization, methodology, investigation S.W.; J.Y.; data curation: S.W.; K.O.; supervision, funding acquisition: J.Y.; formal analysis: S.W.; J.U.; writing—original draft: S.W.; writing一review and editing: J.Y.; S.W.; K.O.

Funding: This research was funded by JSPA KAKENHI, grant number JP16K00668.

Acknowledgments: We are thankful for the reviewers and the editor.

Conflicts of Interest: The authors declare no conflict of interest.

\section{References}

1. UNECE Climate Change and Sustainable Transport. Available online: http://www.unece.org/?id=9890 (accessed on 4 October 2019).

2. Miller, J.D.; Façanha, C. The State of Clean Transport Policy: A 2014 Synthesis of Vehicle and Fuel Policy Developments; International Council on Clean Transportation: Washington, DC, USA, 2014; pp. 1-66.

3. Del Pero, F.; Delogu, M.; Pierini, M. Life Cycle Assessment in the automotive sector: A comparative case study of Internal Combustion Engine (ICE) and electric car. Procedia Struct. Integr. 2018, 12, 521-537. [CrossRef]

4. Yu, P.; Zhang, J.; Yang, D.; Lin, X.; Xu, T. The evolution of China's New Energy Vehicle industry from the perspective of a technology-market-policy framework. Sustainability 2019, 11, 1711.

5. Fuji Keizai Group. Press Release Investigation on Global HV/PHV/EV Sales. 2018. Available online: http: //www.group.fuji-keizai.co.jp/press/pdf/180614_18053.pdf (accessed on 17 August 2018).

6. Next Generation Vehicle Promotion Center Number of EV Sales. Available online: http://www.cev-pc.or.jp/ tokei/hanbai3.html (accessed on 1 September 2019). 
7. Trade Statistics of Japan. Trade Statistic. Available online: http://www.customs.go.jp/toukei/srch/index.htm? $\mathrm{M}=01 \& \mathrm{P}=0$ (accessed on 12 September 2019).

8. Fuse, M.; Kashima, S. Estimation of export volume for end-of-life vehicles from Japan. J. Jpn. Soc. Waste Manag. Expert. 2007, 18, 305-313. [CrossRef]

9. Shioji, H. Abandoned vehicles problem in Pacific Ocean islands countries. Ann. Soc. Ind. Stud. Jpn 2018, 2018, 55-73.

10. Yu, J.; Wang, S.; Toshiki, K.; Serrona, K.R.B.; Fan, G.; Erdenedalai, B. Latest Trends and New Challenges in End-of-life Vehicle Recycling. In Environmental Impacts of Road Vehicles: Past, Present and Future; The Royal Society of Chemistry: London, UK, 2017; pp. 174-213. ISBN 978-1-78262-892-7.

11. Tagliaferri, C.; Evangelisti, S.; Acconcia, F.; Domenech, T.; Ekins, P.; Barletta, D.; Lettieri, P. Life cycle assessment of future electric and hybrid vehicles: A cradle-to-grave systems engineering approach. Chem. Eng. Res. Des. 2016, 112, 298-309. [CrossRef]

12. Richa, K.; Babbitt, C.W.; Nenadic, N.G.; Gaustad, G. Environmental trade-offs across cascading lithium-ion battery life cycles. Int. J. Life Cycle Assess. 2017, 22, 66-81. [CrossRef]

13. Tasaki, T.; Oguchi, M.; Kameya, T.; Urano, K. A prediction method for the number of waste durable goods. J. Jpn. Soc. Waste Manag. Expert 2001, 12, 49-58. [CrossRef]

14. Yano, J.; Muroi, T.; Sakai, S. Rare earth element recovery potentials from end-of-life hybrid electric vehicle components in 2010-2030. J. Mater. Cycles Waste Manag. 2016, 18, 655-664. [CrossRef]

15. Li, Y.; Fujikawa, K. Potential of the renewable resources of End-of-Life vehicles in China. Environ. Sci. 2017, 30, 184-189. [CrossRef] [PubMed]

16. Automobile Inspection \& Registration Information Association. Average serviceable age of vehicle in Japan. Available online: https://www.airia.or.jp/publish/file/r5c6pv000000m20m-att/r5c6pv000000m211.pdf (accessed on 12 September 2019).

17. Terazono, A. End-of-life vehicles. Automobile recycling in Germany. Waste Manag. Res. 2002, 13, $210-220$. [CrossRef]

18. Ministry of Finance Japan Change of Tax Regulation in 2014. Available online: https://www.mof.go.jp/tax policy/publication/brochure/zeisei14/03.htm (accessed on 1 September 2019).

19. Japan Automobile Recycling Promotion Center (JARC). ELV Recycling Data Book 2018. Available online: https: //www.jarc.or.jp/renewal/wp-content/uploads/2019/08/48a86499215838da4069fc61c599d98c.pdf (accessed on 12 September 2019).

20. Automobile Inspection \& Registration Information Association. Transition of Each Kind of Vehicles' Average Age. Available online: https://www.airia.or.jp/publish/file/r5c6pv000000buck-att/r5c6pv000000bucz.pdf (accessed on 11 September 2019).

21. Abe, A. Review of Statistics Related to End-of-Life Vehicles in Japan; Bulletin Number: AN00243983; Bulletin of the Faculty of Education Yamaguchi University: Yamaguchi, Japan, 2014; Volume 63, pp. 1-9.

22. Recruit Carsensor. Market Situation for Sencondhand Vehicle (Prius). Available online: https://www.carsensor. net/usedcar/souba.php?STID=CS211100\&T=1\&BRDC=TO\&CARC=S122 (accessed on 11 September 2019).

23. Nippon Steel Research Institute Corporation. Promotion of the Install of Energy Infrastructure System in 2015: Investigation on the Possibility for Installing Next-Generation Vehicle Recycling System in Mongolia. Available online: https://www.meti.go.jp/meti_lib/report/2016fy/000332.pdf (accessed on 12 September 2019).

24. Denton, T. Electric and Hybrid. Vehicles, 1st ed.; Routledge: New York, NY, USA, 2016; ISBN 978-1-138-84237-3.

25. Toyota Motor Corporation. Questions about Hybrid Vehicle. Available online: https:/toyota.jp/faq/car/all/ about-hybrid/0001.html (accessed on 12 September 2019).

26. Wu, B.; Offer, G.J. Environmental Impact of Hybrid and Electric Vehicles. In Environmental Impacts of Road Vehicles: Past, Present and Future; The Royal Society of Chemistry: London, UK, 2017; pp. 133-156.

27. Japan Automobile Manufacturers Association (JAMA). Generation Situation about the Recycling of Next-Generation Vehicle. Available online: https:/www.meti.go.jp/shingikai/sankoshin/sangyo_gijutsu/ haikibutsu_recycle/jidosha_wg/pdf/046_03_02.pdf (accessed on 12 September 2019).

(C) 2019 by the authors. Licensee MDPI, Basel, Switzerland. This article is an open access article distributed under the terms and conditions of the Creative Commons Attribution (CC BY) license (http://creativecommons.org/licenses/by/4.0/). 